\title{
DIAGNOSIS OF ADMITTED DIABETIC PATIENTS IN A TERTIARY CARE HOSPITAL IN PAKISTAN.
}

1. MBBS, DDM Senior Lecturer Physiology BUMDC, Karachi.

2. MBBS, M.Phil, Ph.D Fellow Professor \& HOD Physiology BUMDC, Karachi.

3. MBBS

House Officer Medicine PN Shifa, Karachi.

4. Masters in Statistics Biostatistician BUMDC.

Correspondence Address: Dr. Rabia Siddiqui

Department of Physiology BUMDC, Karachi.

rabsidd@gmail.com

Article received on: 25/05/2019 Accepted for publication: 03/09/2019
Rabia Siddiqui', Nighat Rukhsana ${ }^{2}$, Najmus Sahar ${ }^{3}$, Muhammad Faisal Fahim ${ }^{4}$

\begin{abstract}
Objectives: An observational study to assess the reasons for admission of diabetic patients in a tertiary care hospital of Pakistan. Study Design: Cross sectional observational study. Setting: Department of Medicine, PN Shifa Hospital, Karachi. Period: June to August 2018. Material \& Methods: All patients admitted to medical ward of PNS Shifa over a period of three months were included in the study. Admissions were done with the primary diagnosis of diabetes in both males and females aged 20-80 years, who were taking some form of hypoglycemic agents (oral or insulin). A questionnaire was formed and filled by the investigator, containing information about demographics details of the patients, duration of diabetes, duration of hospital stay, pre-existing co-morbid conditions and principal reason for admission along with blood parameters (FBS and $\mathrm{HbA1c}$ ). Results: Mean age of admitted patients in both male and females was between 36-40 years. There were more male patients who were hospitalized. Hospital stay in days was longer for men than women. Women had done primary level of education and Men had Secondary level of education. Men had diabetes of 1115 years duration as compared to women who had diabetes of less than 10 years duration. All patients had uncontrolled diabetes despite drug treatment and as depicted by an average $\mathrm{HbA} 1 \mathrm{c}$ of $8.07 \%$. A preexisting history of Hypertension, coronary artery disease, bronchial asthma and dyslipidemia were more prevalent in all diabetic patients. The four most common reasons for hospital admissions Angina/ Acute coronary syndrome, Pneumonia, Stroke and Urinary Tract Infections. Conclusion: This study shows that diabetic patients who were admitted had more male patients and their glycemic control was poor. Diseases of cardiovascular system was the pre-existing co-morbid associated with diabetes. Infection (Pneumonia) was the major cause of hospital admission followed by coronary artery disease (Angina/ Acute coronary syndrome).
\end{abstract}

Key words: Diagnosis, Hospital Admissions, Uncontrolled Diabetes.

Article Citation: Siddiqui R, Rukhsana N, Sahar N, Fahim MF. Diagnosis of admitted diabetic patients in a Tertiary Care Hospital in Pakistan. Professional Med J 2020; 27(5):915-920. DOI: 10.29309/TPMJ/2020.27.05.3690

\section{INTRODUCTION}

According to the World Health Organization report, of the many noncommunicable diseases cardiovascular diseases, stroke, diabetes, cancers and chronic respiratory diseases are responsible for $71 \%$ of all deaths globally. ${ }^{1}$ Patients with diabetes have a 3 times greater chance of hospitalization compared to those not having diabetes. ${ }^{2}$ In 2018, the International Diabetes federation (IDF) calculated the global burden of diabetes for the year 2017 and 2045. It was estimated that in 2017, $8.8 \%$ of adults (aged 20-79) would be suffering from diabetes mellitus affecting 451 million in the world and it will increase to $10.4 \%$ by 2040 affecting 693 million adults. ${ }^{3}$ Type 1 and Type 2 diabetes are two types of diabetes and the percentage of people suffering from type 2 diabetes is on the rise in most countries. Most of the people with diabetes are between 40 and 59 years of age. About 1 in 2 (212 million) people with diabetes remain undiagnosed. According to IDF 2017 report 39 million people in Middle East and North Africa suffer from diabetes. This figure would increase by $110 \%$ in 2045 to 82 million people suffering from diabetes. ${ }^{4}$

Diabetes is a financial burden to the patient and associated with a high morbidity and mortality. Late diagnosis of diabetes or ineffective treatment may lead to complications including cardiovascular, cerebrovascular and peripheral vascular disease, 
neuropathy, infection and lower extremity amputation. Risk factors for diabetes include poor glycemic control, long duration of diabetes with associated pre-existing co-morbidities. ${ }^{5}$ Most hospitalizations are preventable by improving the primary care setting for diabetic patients. ${ }^{6}$

If diabetes is detected early by annual screening in high risk patients and upon diagnosis appropriately treating with medications, educating patients about diabetes and its complications, introducing effective immunizations against common respiratory infections: all of this will contribute to decreasing diabetes related hospitalizations. ${ }^{7}$ There are variable reasons for admission to a hospital in patients with diabetes according to various studies namely one done in Kuwait $^{8}$ shows cardiovascular diseases to be more common reason for diabetic hospitalizations. The most common system affected for admission to a hospital of a diabetic patient was respiratory system followed by GIT according to one report from Nepal. ${ }^{9}$ This study was carried out to determine the common reasons for hospitalizations in adults with diabetes.

\section{MATERIAL \& METHODS}

A cross sectional study was conducted over a period of three months from June to August 2018 in the Department of Medicine at PN Shifa Hospital, Karachi. Admissions were done with the primary diagnosis of diabetes in both males and females aged $20-80$ years, who were taking some form of hypoglycemic agents (oral or insulin). A questionnaire was formed and filled by the investigator, containing information about demographics details of the patients, duration of diabetes, duration of hospital stay, pre-existing comorbid conditions (hypertension, dyslipidemia, coronary artery disease and cerebrovascular disease) and principal reason for admission along with blood parameters (FBS and HbA1c).

\section{Inclusion Criteria}

Patients of either sex aged $\geq 20$ years and above, who are diagnosed to have Type 1 or type 2 diabetes, with more than six months duration and above. For patients who were admitted more than once, only first admission was included.
Associated pre-existing history of hypertension, dyslipidemia, coronary heart disease, or cerebrovascular disease was also reviewed.

Patients with below 20 years of age, patients without diabetes, very ill/elderly patients (>80 years) and patients with gestational diabetes. Patients were excluded from the study if they did not have a clear diagnosis at the time of discharge.

Data Analysis was done through SPSS version 23.0. Continuous variables were presented as means $\pm S D$, whereas categorical variables were presented as frequency and percentages. An Independent sample t-test was applied to see the significance between gender vs Duration of stay (days), HbA1c and FBS. Chi-square test was used to test for differences in proportion between categorical variables. P-value of $<=0.05$ considered to be statistically significant.

\section{RESULTS}

The mean age of admitted diabetic patients for both males and females was between 3640 years. A total of 110 patients were included, out of which $79(71 \%)$ were males and $31(28 \%)$ were females (0.902). There were more male patients who were hospitalized as compared to women. Mean Hospital stay was longer 11.2 \pm 5.2 days for males and $8.19 \pm 4.4$ days for females (0.006). Males had completed secondary level of education 33(41.8\%) and 14 (45.2\%) females had done primary level of education.

A large percentage of both groups were married, 52males (65.8\%) and 19 females (61.3\%). Although out of all diabetic patients, 11(35.5\%) females were widowed, while 21 (26.6\%) males were single (0.000). Most of the patients in diabetic group were suffering from Type $2 \mathrm{D} / \mathrm{M}$, $75(94.9 \%)$ males and 31(100\%) females (0.202).

Most of the male patients $43(54.4 \%)$ had diabetes of $11-15$ years duration while females $14(45.2 \%)$ had 6-10 years duration of diabetes (0.007).

All male and female patients had poor glycemic control, HbA1c $8.07 \%$ despite on oral hypoglycemic agents or insulin (0.174). 
A pre-existing disease of Hypertension, 74 patients (67.2\%), Coronary heart disease, 41(37.2\%), Bronchial Asthma, 12(10.9\%) and dyslipidemia, $10(9.09 \%)$ are the common co-morbid conditions associated with diabetes.

Diagnosis of all admitted patients is given in Table-l. The most common cause was of some form of infections, commonest (23.6\%) being Pneumonia and (10\%) being urinary tract infections and Tuberculosis (8.1\%). The second most common cause of admission to hospitals was Acute Coronary Syndrome/ Angina (22.7\%). The third commonest cause was Stroke in $13(11.8 \%)$ patients.

\begin{tabular}{|l|c|}
\hline \multicolumn{1}{|c|}{ Diagnosis } & N (\%) \\
\hline Pneumonia & $26(23.6 \%)$ \\
\hline ACS/Angina & $25(22.7 \%)$ \\
\hline Stroke & $13(11.8 \%)$ \\
\hline UTI & $11(10 \%)$ \\
\hline Tuberculosis & $9(8.1 \%)$ \\
\hline Bronchiectasis & $7(6.3 \%)$ \\
\hline CCF & $6(5.4 \%)$ \\
\hline Diabetes with abscess & $5(4.5 \%)$ \\
\hline Diabetic foot & $4(3.6 \%)$ \\
\hline Acute exacerbation of asthma & $4(3.6 \%)$ \\
\hline Nephritic Syndrome & $3(2.7 \%)$ \\
\hline Diabetic Ketoacidosis & $2(1.8 \%)$ \\
\hline Renal Failure & $2(1.8 \%)$ \\
\hline Nephrotic Syndrome & $2(1.8 \%)$ \\
\hline Gall stones / Cholecystitis & $2(1.8 \%)$ \\
\hline COPD & $1(0.9 \%)$ \\
\hline Chronic Liver disease & $1(0.9 \%)$ \\
\hline Acute Hepatitis & $1(0.9 \%)$ \\
\hline Pulmonary edema & $1(0.9 \%)$ \\
\hline HONKS Diabetes & $1(0.9 \%)$ \\
\hline Table-I. Diagnosis of diabetic admitted patients \\
\hline
\end{tabular}

\section{Result}

\begin{tabular}{|c|c|c|c|}
\hline \multirow{2}{*}{ Age } & \multicolumn{2}{|c|}{ Gender } & \multirow{2}{*}{$\begin{array}{c}\text { P. } \\
\text { Value }\end{array}$} \\
\hline & $\begin{array}{c}\text { Male } \\
(n=79)\end{array}$ & $\begin{array}{l}\text { Female } \\
(n=31)\end{array}$ & \\
\hline $10-25$ & 1 (1.3\%) & $0(0.0 \%)$ & \multirow{4}{*}{0.902} \\
\hline $26-35$ & 9 (11.4\%) & $3(9.7 \%)$ & \\
\hline $36-40$ & $37(46.8 \%)$ & $16(51.6 \%)$ & \\
\hline 50 or above & $32(40.5 \%)$ & 12 (38.7\%) & \\
\hline $\begin{array}{l}\text { Hospital Stay } \\
\text { (Days) }\end{array}$ & $11.22 \pm 5.2$ & $8.19 \pm 4.4$ & 0.006 \\
\hline \multicolumn{4}{|l|}{ Education } \\
\hline Literate & $5(6.3 \%)$ & 5 (16.1\%) & \multirow{5}{*}{0.218} \\
\hline Primary & 27 (34.2\%) & $14(45.2 \%)$ & \\
\hline Secondary & $33(41.8 \%)$ & $9(29.0 \%)$ & \\
\hline Intermediate & $10(12.7 \%)$ & $3(9.7 \%)$ & \\
\hline Graduate & $4(5.1 \%)$ & $0(0.0 \%)$ & \\
\hline \multicolumn{4}{|l|}{ Marital Status } \\
\hline Married & 52 (65.8\%) & $19(61.3 \%)$ & \multirow{3}{*}{0.000} \\
\hline Widowed & $6(7.6 \%)$ & $11(35.5 \%)$ & \\
\hline Single & $21(26.6 \%)$ & $1(3.2 \%)$ & \\
\hline \multicolumn{4}{|c|}{ Type of Diabetes } \\
\hline Type 1 & $4(5.1 \%)$ & $0(0.0 \%)$ & \multirow{2}{*}{0.202} \\
\hline Type 2 & 75 (94.9\%) & 31 (100\%) & \\
\hline \multicolumn{4}{|c|}{ Duration of Diabetes (years) } \\
\hline $0-5$ & $6(7.6 \%)$ & $1(3.2 \%)$ & \multirow{4}{*}{0.007} \\
\hline $6-10$ & 16 (20.3\%) & 14 (45.2\%) & \\
\hline $11-15$ & $43(54.4 \%)$ & $7(22.6 \%)$ & \\
\hline$>15$ & 14 (17.7\%) & $9(29.0 \%)$ & \\
\hline
\end{tabular}




\begin{tabular}{|c|c|c|c|c|}
\hline & \multicolumn{2}{|c|}{ Gender } & \multirow{2}{*}{$\begin{array}{c}\text { P- } \\
\text { Value }\end{array}$} \\
\hline & & Male & Female & \\
\hline \multicolumn{2}{|l|}{ FBS } & $145.5 \pm 25.5$ & $148.8 \pm 35.4$ & 0.584 \\
\hline \multicolumn{2}{|l|}{ HBA1c } & $8.07 \pm 0.6$ & $8.26 \pm 0.7$ & 0.174 \\
\hline \multirow{2}{*}{$\begin{array}{l}\text { Diabetes as } \\
\text { a Principal } \\
\text { diagnosis with } \\
\text { diabetic foot }\end{array}$} & No & 74 (93.7\%) & 31 (100.0\%) & \multirow{2}{*}{0.152} \\
\hline & Yes & $5(6.3 \%)$ & $0(0.0 \%)$ & \\
\hline \multirow{2}{*}{$\begin{array}{l}\text { Diabetes and } \\
\text { involvement of } \\
\text { CVS }\end{array}$} & No & 75 (94.9\%) & 29 (93.5\%) & \multirow{2}{*}{0.773} \\
\hline & Yes & $4(5.1 \%)$ & $2(6.5 \%)$ & \\
\hline \multirow{2}{*}{$\begin{array}{l}\text { Diabetes and } \\
\text { involvement } \\
\text { of Respiratory } \\
\text { system }\end{array}$} & No & $61(77.2 \%)$ & 24 (77.4\%) & \multirow{2}{*}{0.982} \\
\hline & Yes & $18(22.8 \%)$ & 7 (22.6\%) & \\
\hline \multirow{2}{*}{$\begin{array}{l}\text { Diabetes and } \\
\text { involvement of } \\
\text { urinary system }\end{array}$} & No & $68(86.1 \%)$ & 24 (77.4\%) & \multirow{2}{*}{0.27} \\
\hline & Yes & 11 (13.9\%) & 7 (22.6\%) & \\
\hline \multirow{2}{*}{$\begin{array}{l}\text { Diabetes and } \\
\text { abscesses }\end{array}$} & No & 74 (93.7\%) & 31 (100.0\%) & \multirow{2}{*}{0.152} \\
\hline & Yes & $5(6.3 \%)$ & $0(0.0 \%)$ & \\
\hline \multirow{2}{*}{$\begin{array}{l}\text { Diabetes and } \\
\text { Pneumonia }\end{array}$} & No & 65 (82.3\%) & $20(64.5 \%)$ & \multirow{2}{*}{0.046} \\
\hline & Yes & 14 (17.7\%) & 11 (35.5\%) & \\
\hline \multirow{2}{*}{$\begin{array}{l}\text { Diabetes and } \\
\text { CCF }\end{array}$} & No & 77 (97.5\%) & 28 (90.3\%) & \multirow{2}{*}{0.106} \\
\hline & Yes & $2(2.5 \%)$ & $3(9.7 \%)$ & \\
\hline \multirow{2}{*}{$\begin{array}{l}\text { Diabetes and } \\
\text { COPD }\end{array}$} & No & 74 (93.7\%) & 30 (96.8\%) & \multirow{2}{*}{0.519} \\
\hline & Yes & $5(6.3 \%)$ & $1(3.2 \%)$ & \\
\hline \multirow{2}{*}{$\begin{array}{l}\text { Diabetes } \\
\text { and Acute } \\
\text { Coronary } \\
\text { syndrome }\end{array}$} & No & $59(74.7 \%)$ & 27 (87.1\%) & \multirow{2}{*}{0.156} \\
\hline & Yes & $20(25.3 \%)$ & 4 (12.9\%) & \\
\hline \multirow{2}{*}{$\begin{array}{l}\text { Diabetes and } \\
\text { stroke }\end{array}$} & No & $68(86.1 \%)$ & 29 (93.5\%) & \multirow{2}{*}{0.275} \\
\hline & Yes & 11 (13.9\%) & 2 (6.5\%) & \\
\hline \multirow{2}{*}{$\begin{array}{l}\text { HONKS } \\
\text { diabetes }\end{array}$} & No & 78 (98.7\%) & $31(100.0 \%)$ & \multirow{2}{*}{0.529} \\
\hline & Yes & 1 (1.3\%) & $0(0.0 \%)$ & \\
\hline \multirow{2}{*}{$\begin{array}{l}\text { Diabetic } \\
\text { ketoacidosis }\end{array}$} & No & 77 (97.5\%) & 31 (100.0\%) & \multirow{2}{*}{0.371} \\
\hline & Yes & $2(2.5 \%)$ & $0(0.0 \%)$ & \\
\hline \multirow{2}{*}{ ORAL } & No & 9 (11.4\%) & $3(9.7 \%)$ & \multirow{2}{*}{0.795} \\
\hline & Yes & 70 (88.6\%) & 28 (90.3\%) & \\
\hline & No & $62(78.5 \%)$ & 29 (93.5\%) & \\
\hline ivouliv & Yes & 17 (21.5\%) & 2 (6.5\%) & \\
\hline
\end{tabular}

\section{DISCUSSION}

Conditions such as diabetes, pneumonia and congestive heart failure are preventable and avoidable conditions for hospitalizations. Observations suggest that hospitalizations for diabetic patients are three time more frequent as compared to persons without diabetes and also increases the demand for hospital services particularly for macroangiopathy, ophthalmic, renal problems and peripheral circulatory disorders. ${ }^{10}$

The mean age of both males and females was between 36-40 years which is surprising as type 2 diabetes mellitus is more prevalent after 40 years. But this is not supported by one Kuwaiti study where $97 \%$ of type 2 diabetic patients were 60 years and older. ${ }^{8}$

Hospitalized patients were mostly men (71\%) which may be because of early seeking of treatment options by men as compared to women depending on behavioral upbringing and cultural determinants. One Nepali study had more females (56.5\%) as admitted patients than males $(43.5 \%) .{ }^{9}$

The average length of hospital stay was more for men (11 days) than women (8 days). According to one study, contrary to our findings, average length of stay was of 8.3 days. ${ }^{11}$ As all admitted patients had uncontrollable diabetes (HbA1c-8.0\%) with added secondary diagnosis of some complications of diabetes, this could be due to long management of these conditions that the hospital stay was longer for diabetic patients as compared to non-diabetic patients. According to one study, there were no significant differences between the men and women patients with regard to age, length of hospital stay, 2-h postprandial glucose at admission or discharge, HbA1c level, body mass index, or waist-to-hip ratio. ${ }^{12-14}$

All diabetic patients who were admitted had a less than Intermediate education, with men completing secondary level and women completing primary level of education. This finding is consistent with the low literacy rate in Pakistan. 
Most of the patients (97\%) of males and (100\%) of females had type 2 diabetes mellitus. This is in consistent with Kuwaiti study where $97 \%$ of patients also had type 2 diabetes mellitus. ${ }^{8}$

Ten to fifteen years was the duration of diabetes for male patients and it was less than ten years for female patients. Researchers have discovered that men at a lower BMl are more prone to develop type 2 diabetes than women at a comparable age.

All patients both male and female had uncontrolled diabetes as depicted by high $\mathrm{HbA} 1 \mathrm{c}$ of $8.0 \%$ which could be due to poor compliance, under drug treatment, poor blood sugar monitoring at home ,reduced hospital visits for follow up and lack or diabetes education for vigilant diabetic control of blood sugar.

Associated co-morbid conditions in diabetic patients in our setting, was hypertension, coronary heart disease, bronchial asthma and dyslipidemia which is in accordance with one study where hypertension, dyslipidemia, bronchial asthma and cerebrovascular diseases was more prevalent among diabetic patients. ${ }^{8}$

The prevalence of infections is being reported to be high among diabetic patients. ${ }^{15}$ Our study indicated that the most common cause for hospitalizations for diabetic patients were infections of some kind mainly pneumonia, urinary tract infections and tuberculosis. One Spanish data showed that CAP incidence seems to be increasing at a higher rate among patients with T2DM than among non-diabetic patients in cases studied from 2004-2013. ${ }^{9}$ Pneumonia occurring at a higher rate could be due to rate of vaccination of diabetic patients is low. Public and general practitioners' awareness for appropriate vaccination is needed to reduce morbidity and mortality from this condition. The second common cause was Acute Coronary Syndrome /Angina and third being Stroke. A majority of diabetic patients were suffering from cardiovascular and respiratory diseases as shown by one study. ${ }^{8}$ Again infection was the most common cause of admission of diabetic patients being urinary tract infection along with coronary heart disease, which is in accordance with our study. Diabetes mellitus substantially increases the risk of death, ischemic events, and heart failure. Cardiovascular diseases, especially heart failure and coronary heart disease appeared as dominant reasons for hospitalizations in one study. ${ }^{16,17}$

\section{CONCLUSION}

More male patients were admitted with poor glycemic control. Diseases of cardiovascular system was the pre-existing co-morbid condition associated with diabetes. Infection (Pneumonia) was the major cause of hospital admission followed by Coronary artery disease/Angina.

Copyright $\odot 03$ Sep, 2019.

\section{REFERENCES}

1. Whoint. [Online]. Available from: https://www.who.int/ news-room/fact-sheets/detail/the-top-10-causes-ofdeath [Accessed 25 August 2019].

2. Marco Falcone, Giusy Tiseo, Alessandro Russo, Laura Giordo, Elisa Manzini, Giuliano Bertazzoni et al. Hospitalization for pneumonia is associated with decreased 1-year survival in patients with type 2 diabetes results from a prospective cohort study. Medicine (Baltimore). 2016; 95(5):1-8.

3. K.Ogurtsova, J.D da Rocha Fernandes, Y. Huang, U. Linnenkamp, L. Guariguata, N.H. Cho, et al IDF Diabetes Atlas: Global estimates for the prevalence of diabetes for 2015 and 2040. Diabetes Research and Clinical practice. 2017; 128:40-50.: Global estimates for the prevalence of diabetes for 2015 and 2040 International Diabetes Atlas.

4. Abegunde DO, Mathers CD, Adam T, Ortegan M, Strong $\mathrm{K}$ : The burden and costs of chronic diseases in the low income and middle-income countries. Lancet 2007, 370:1929-1938.

5. Herman W. The global burden of diabetes: An overview. Diabetes Mellitus in Developing Countries and Underserved Communities. 2016; 1-5.

6. Clarke PM, Glasziou P, Patel A, Chalmers J, Woodward M, Harrap SB, Salomon JA, ADVANCE Collaborative Group. Event rates, hospital utilization, and costs associated with major complications of diabetes: a multicountry comparative analysis. PLOS medicine. 2010 Feb;7(2). 
7. Andrea L.C. Schneider,, Rita R. Kalyani, Sherita Golden, Sally C. Stearns, Lisa Wruck, Hsin Chieh Yeh, Josef Coresh, and Elizabeth Selvin, Diabetes and prediabetes and risk of hospitalization: The Atherosclerosis Risk in Communities (ARIC) Study Diabetes Care 2016; 39:772-779.

8. Al-Adsani AM, Abdulla KA. Reasons for hospitalizations in adults with diabetes in Kuwait. International Journal of Diabetes Mellitus. 2015 May 1; 3(1):65-9.

9. Ana López-de-Andrés, Javier de Miguel-Díez, Isabel Jiménez-Trujillo, Valentín Hernández-Barrera, José M de Miguel-Yanes, Manuel Méndez-Bailón, Napoleón PérezFarinós, Miguel Á ngel Salinero-Fort, Rodrigo JiménezGarcía, Hospitalisation with community acquired pneumonia among patients with type 2 diabetes: An observational population-based study in Spain from 2004 to 2013. BMJ Open 2017; 7:e013097.

10. Tomlin AM, Tilyard MW, Dovey SM, Dawson AG. Hospital admissions in diabetic and non-diabetic patients: a case-control study. Diabetes research and clinical practice. 2006 Sep 1;73(3):260-7.

11. Comino et al. BMC Health Services Research (2015) 15:12.

12. Campbell RK. Etiology and effect on outcomes of hyperglycemia in hospitalized patients. Am J Health Syst Pharm 2007; 64(6):S4-8.
13. Lin W, Chen C, Guan H, Du X, Li J. Hospitalization of elderly diabetic patients: characteristics, reasons for admission, and gender differences. BMC geriatrics. 2016 Dec;16(1):160.

14. J. M. Khalid, M. Raluy-Callado, B. H. Curtis, K. S. Boye, A. Maguire, M. Reaney. Rates and risk of hospitalization among patients with type 2 diabetes: Retrospective cohort study using the UK General Practice Research Database linked to English Hospital Episode Statistics. Int J Clin Pract, January 2014; 68, 1:40-48.

15. P Adhikari, UN Pathak and N Subedi, Common reasons for hospitalization among adult patients with diabetes in a private medical college in Kathmandu. Nepal Med Coll J 2012; 14(4): 316-319.

16. Cavender et al. Impact of diabetes mellitus on hospitalization for heart failure, cardiovascular events, and death outcomes at 4 years from the reduction of atherothrombosis for continued health (REACH) registry. Circulation. 2015; 132:923-931.

17. Cook et al. Common reasons for hospitalization in urban diabetes patients. Ethnicity and Disease, 2006; 16:391-397.

\begin{tabular}{|c|c|c|c|}
\hline \multicolumn{4}{|c|}{ AUTHORSHIP AND CONTRIBUTION DECLARATION } \\
\hline Sr. \# & Author(s) Full Name & Contribution to the paper & Author(s) Signature \\
\hline 1 & Rabia Siddiqui & $\begin{array}{l}\text { Concept \& design of work, } \\
\text { Accountable for all aspects, } \\
\text { Drafting of work. }\end{array}$ & Rabia Siddique \\
\hline 2 & & $\begin{array}{l}\text { Critical review \& final approval } \\
\text { of work. }\end{array}$ & Pिg \\
\hline 3 & Najmus Sahar & Data aquisition. & Sabar Asit \\
\hline 4 & M. Faisal Fahim & $\begin{array}{l}\text { Data analysis and } \\
\text { interpretation. }\end{array}$ & An \\
\hline
\end{tabular}

